\title{
Palaeospondylus as a primitive hagfish
}

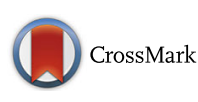

\author{
Tatsuya Hirasawa ${ }^{1 *}$, Yasuhiro Oisi ${ }^{2}$ and Shigeru Kuratani ${ }^{1}$
}

\begin{abstract}
Background: The taxonomic position of the Middle Devonian fish-like animal Palaeospondylus has remained enigmatic, due mainly to the inability to identify homologous cranial elements. This animal has been classified into nearly all of the major vertebrate taxa over a century of heuristic taxonomic research, despite the lack of conclusive morphological evidence.

Results: Here we report the first comparative morphological analysis of hagfish embryos and Palaeospondy/us, and a hitherto overlooked resemblance in the chondrocranial elements of these animals; i.e., congruence in the arrangement of the nasal capsule, neurocranium and mandibular arch-derived velar bar. The large ventral skeletal complex of Palaeospondylus is identified as a cyclostome-specific lingual apparatus. Importantly, the overall morphological pattern of the Palaeospondylus cranium coincides well with the cyclostome pattern of craniofacial development, which is not shared with that of crown gnathostomes. Previously, the presence of the vertebral column in Palaeospondylus made its assignment problematic, but the recent identification of this vertebral element in hagfish is consistent with an affinity between this group and Palaeospondylus.
\end{abstract}

Conclusion: These lines of evidence support the hagfish affinity of Palaeospondylus. Moreover, based on the less specialized features in its cranial morphology, we conclude that Palaeospondylus is likely a stem hagfish.

Keywords: Cyclostomes, Devonian, Fossil taxa, Hagfish, Homology, Palaeospondylus

\section{Background}

Palaeospondylus gunni [1] from the Middle Devonian of Scotland (Fig. 1, Additional file 1: Figure S1, Additional file 2: Figure S2) has long been an enigmatic fossil in vertebrate palaeontology [1-11]. Over the past 125 years, attempts have been made to classify this fossil as a cyclostome [1, 6, 8], frog tadpole [2], lungfish larva $[3,7,10]$, holocephalan [4], elasmobranch [5], placoderm [9], and even a secondarily boneless osteichthyan [11]; however, none of these assignments has been supported by conclusive evidence [11-13]. This problem has been attributed to an inability to homologize its skeletal elements [14], and previous hypotheses have never successfully explained its anatomical configuration. Indeed, the arrangement of skeletal elements of Palaeospondylus has never yet been integrally compared to any of the actual ontogenetic stages of certain taxa.

Morphological homology [15-17] is not recognized $a$ priori, but is adopted when the topographical

\footnotetext{
*Correspondence: hirasawa@cdb.riken.jp

${ }^{1}$ Evolutionary Morphology Laboratory, RIKEN, 2-2-3 Minatojima-minami,

Chuo-ku, Kobe, Hyogo 650-0047, Japan

Full list of author information is available at the end of the article
}

relationships among a series of comparable body parts are found consistently, through heuristic search, in a certain clade. Logically, cladistic analyses cannot be applied prior to the identification of homologies $[15,18]$, and it is difficult to undertake a dynamic homology approach [19] when analyzing unintelligible morphological data. Unlike molecular-based phylogenetic analyses utilizing discrete characters (base or amino acid sequences), most morphology-based analyses require anatomical realization for alignments of corresponding units, that is, character codings. For yet-unassigned fossil taxa, such as Palaeospondylus, the discovery of the most parsimonious set of homologous body parts is the only solution to the classification problem [14].

Until recently, a lack of morphological data in hagfish, developmental data in particular, has prevented the heuristic search for homologies in entire vertebrate groups. Recent studies of the embryonic development of the hagfish [20-23] have gone some way to addressing this deficiency. Analyses of the embryonic development of the hagfish resolved the disparity in cranial morphology of vertebrates $[22,24]$, and for the first time, made it possible to compare the cranial skeleton of Palaeospondylus 


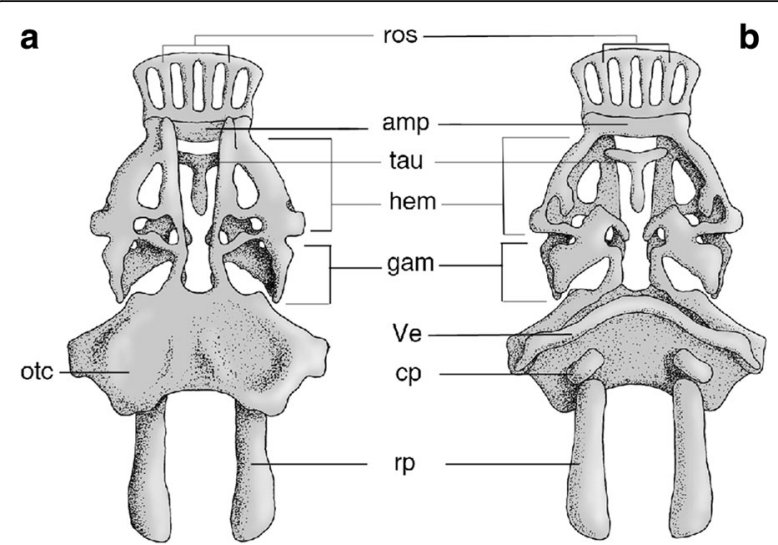

Fig. 1 Cranial skeletons of Palaeospondylus. a,b Restoration of Palaeospondylus gunni cranial skeleton in dorsal (a) and ventral (b) views. amp, ampyx; cp, caudal plate; gam, gammation; hem, hemidome; otc, otic capsule; ros, rostralia; rp, rostral plate; tau, tauidion; Ve, V-shaped element

with those of a wide range of vertebrate groups. Between the cyclostomes and crown gnathostomes (jawed gnathostomes), there is a profound disparity in craniofacial pattern, which originates from the difference in arrangement of craniofacial primordia during embryonic development $[22,24]$. Importantly, although the cyclostome pattern likely represents the ancestral condition for the vertebrates as an entire group, crown gnathostome development does not follow the cyclostome pattern [22, 24]. Based on this disparity, which is due to the complete loss of some vertebrate plesiomorphies in the crown gnathostomes, the possibility of the crown gnathostome affinity of a certain taxon can be eliminated by identifying a set of homologous elements seen in the extant cyclostomes.

From the perspective of morphological disparity, classification of the enigmatic taxon Palaeospondylus into a higher taxonomic group within the vertebrates is achievable through the identification of congruence in arrangement of a suite of homologous elements. Attempts to identify homologous elements between Palaeospondylus and various vertebrate groups have been made, but the hagfish embryo has remained unexamined. In this study, we compared embryos of the inshore hagfish Eptatretus burgeri and Palaeospondylus, focusing on phylogenetically informative features, and discovered homologous skeletal parts between them.

\section{Methods}

\section{Observation of hagfish embryos}

Embryos of the inshore hagfish Eptatretus burgeri were collected according to the developmental stage table of [25], as described previously [20]. In this study, we reexamined three-dimensional models reconstructed from the serial histological sections of the hagfish embryos previously [22, 23].

\section{Observation of Palaeospondylus fossils}

Specimens of Palaeospondylus were observed using a stereomicroscope (M7A, Wild, Heerbrugg, Switzerland) at the American Museum of Natural History (AMNH), New York, USA. Images were taken using a digital camera (E-PL6, Olympus Corp., Tokyo, Japan) mounted on the stereomicroscope via an adaptor (NY-1S, Microscope Network Co., Ltd., Saitama, Japan). The specimens of Palaeospondylus expose either dorsal or ventral aspects of their cranial skeletons on the slabs. Based on positional relationship to vertebral column, which lay dorsally in the live body, we identified dorsal and ventral views of the Palaeospondylus cranial skeletons on the slabs.

\section{Results}

Key features in the embryonic development of the modern hagfish Eptatretus

In E. burgeri embryos at stages 53-60 (Fig. 2a-d), the neurocranium consists of two pairs of longitudinal bars with transverse commissures and processes, rostrally attached to the nasal capsule. Caudally, the longitudinal bars are contiguous to the otic capsule, which continues medially to the parachordal that surrounds the rostral part of the notochord (Fig. 2a, b). From the boundary between the neurocranium and otic capsule, a pair of velar bars grows ventromedially, and later, by stage 53, becoming fused at the median plane to form a $\mathrm{V}$-shaped element. The dental plate of the oral apparatus is located below the neurocranium, associated with the rostral part of the lingual plate that supports the muscles of the cyclostome 'tongue' [22]. The topographical relationships between these cranial elements in hagfish embryos continue to change over the course of development [23]. Prior to hatching, the nasal capsule grows cartilages supporting the rostrally extended nasal duct (Fig. 2e). Simultaneously, cartilages in the oronasal septum extend rostrally, and supporting cartilages arise within tentacles, features that are specific to adult individuals in all known hagfish species. These changes result in a caudad shift in the relative position of the nasal capsule in the cranium.

\section{Homologies between Eptatretus and Palaeospondylus}

As in cyclostomes, the cranium of Palaeospondylus is generally believed to consist of endoskeletal elements $[5,8,9]$. In many Palaeospondylus specimens, the vertebral column is preserved, and it is generally accepted that the massive skeletal element at the level of the first vertebral element represents the otic capsule [3-9] (Figs. 1 and $3 \mathrm{a}, \mathrm{b}$, Additional file 1: Figure S1, Additional file 2: Figure S2). We use this feature as a landmark in our identification of other skeletal elements in this species. Our observations (Additional file 1: Figure S1) and a review of the literature $[5,8,26]$ (Additional file 2: Figure S2) 


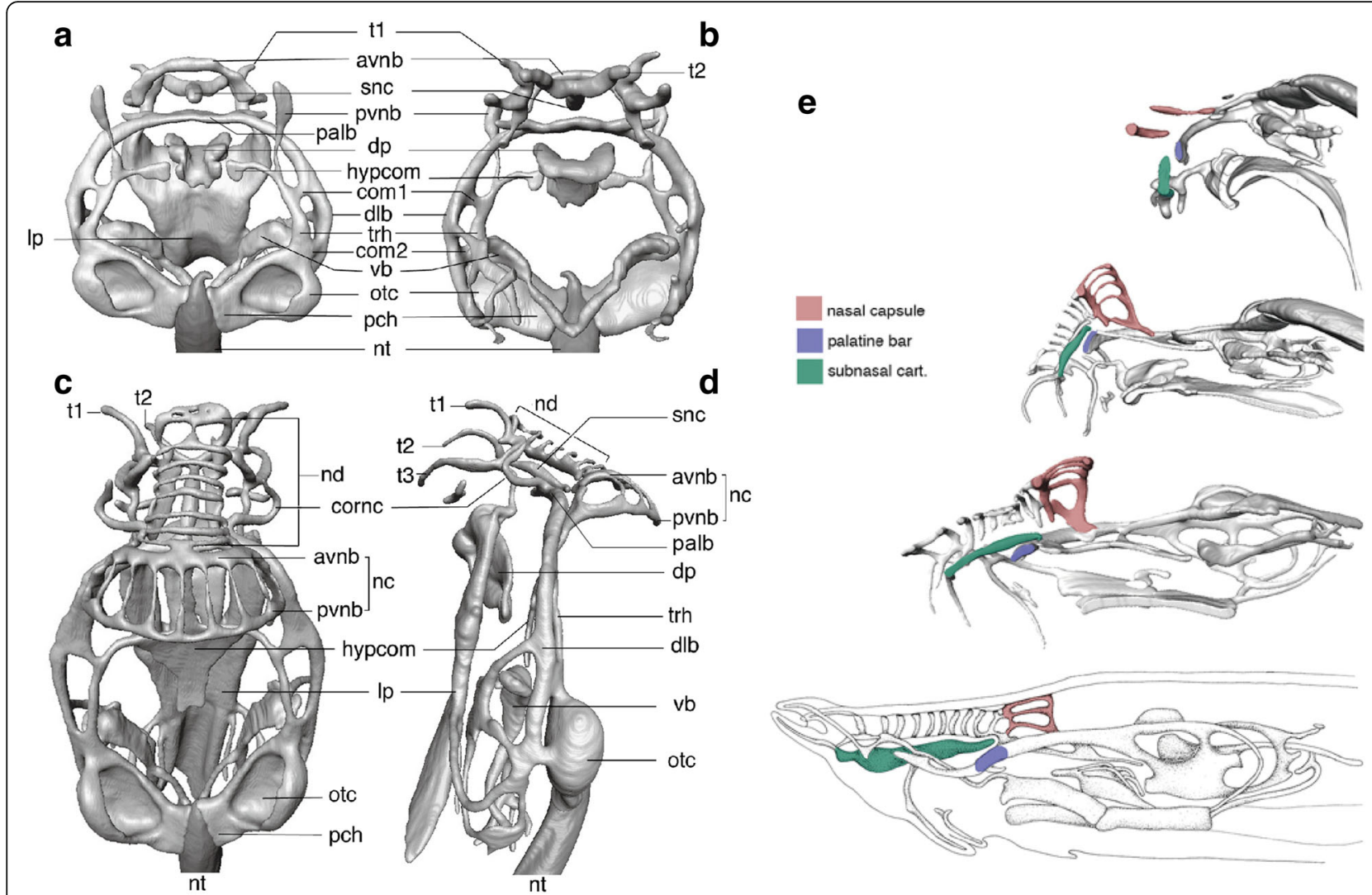

Fig. 2 Cranial skeletons of the Eptatretus embryo. a Eptatretus burgeri embryo at stage 53 in dorsal view. b E. burgeri embryo at stage 53 in ventral view. c E. burgeri embryo at stage 60 in dorsal view. d E. burgeri embryo at stage 60 in left lateral view. e Relative growth of the developing hagfish chondrocrania. From top to bottom, stage 53, stage 60, prehatching and adult hagfish crania. Note, due to the rostral growth of the snout by addition of nasal duct cartilage and extension of subnasal cartilage (green), that the position of the nasal capsule (red) shifts relatively caudal through development. The palatine bar, or the transverse commissure on the rostral tip of the dorsal longitudinal bar, is colored blue for the reference. avnb, anterior vertical nasal bar; com1, 2, commissures of dlb; cornc, cornual cartilage; dlb, dorsal longitudinal bar; dp, dental plate; hypcom, hypophyseal commissure; Ip, lingual plate; nc, nasal capsule; nd, nasal duct cartilage; nt, notochord; otc, otic capsule; palb, palatine bar; pch, parachordal; pvnb, posterior vertical nasal bar; rp, rostral plate; snc, subnasal cartilage; t1-3, cartilaginous support for tentacles; trh, trabecula of hagfish; vb, velar bar

indicate that Palaeospondylus possessed a neurocranium comparable to that of the hagfish embryo, in terms of the possession of two pairs of longitudinal bars (the dorsal longitudinal bar and hagfish trabecula), the palatine bar, and other commissures connecting these bars (Figs. 2 and $3 \mathrm{a}, \mathrm{b})$. Rostrally, several (presumably six) longitudinal bars run in parallel ('rostralia' in the previous description [5]; Fig. 1a, Additional file 1: Figure S1, Additional file 2: Figure S2). These bars are contiguous caudally with a transverse bar and are expanded towards the rostral end to contact with adjacent elements (Fig. 1a, Additional file 1: Figure S1, Additional file 2: Figure S2), forming a cageshaped structure $[5,9]$. The shape and position of this structure, and in particular the presence of both the anterior and posterior transverse bars, show strong morphological similarities with those of the nasal capsule in the hagfish embryo (Fig. 3a). The nasal capsule of Palaeospondylus was previously identified at a lateral part of the neurocranium ('hemidome') [10], but in that model, the other neurocranial elements, including the trabeculae (in this case, the trabecula of crown gnathostomes), could not be identified. In contrast, the homologization between Palaeospondylus and the hagfish embryo described above succeeds in identifying each skeletal element at a comparable position.

The ventral V-shaped element in Palaeospondylus (Fig. 1b, Additional file 1: Figure S1, Additional file 2: Figure S2) resembles the velar bar of the hagfish embryo, as both elements are suspended ventrally at the level of the junction between the neurocranium and otic capsule (Fig. 3b). The midline of the V-shaped element of Palaeospondylus is mostly unfused, but this does not contradict the homology as, in the hagfish embryo, the velar bar develops from paired cartilages and later becomes fused at the median plane by stage 53 . In some previous studies, this element has been identified as the gnathostome ceratohyal [8, 9]; however, this fails to 


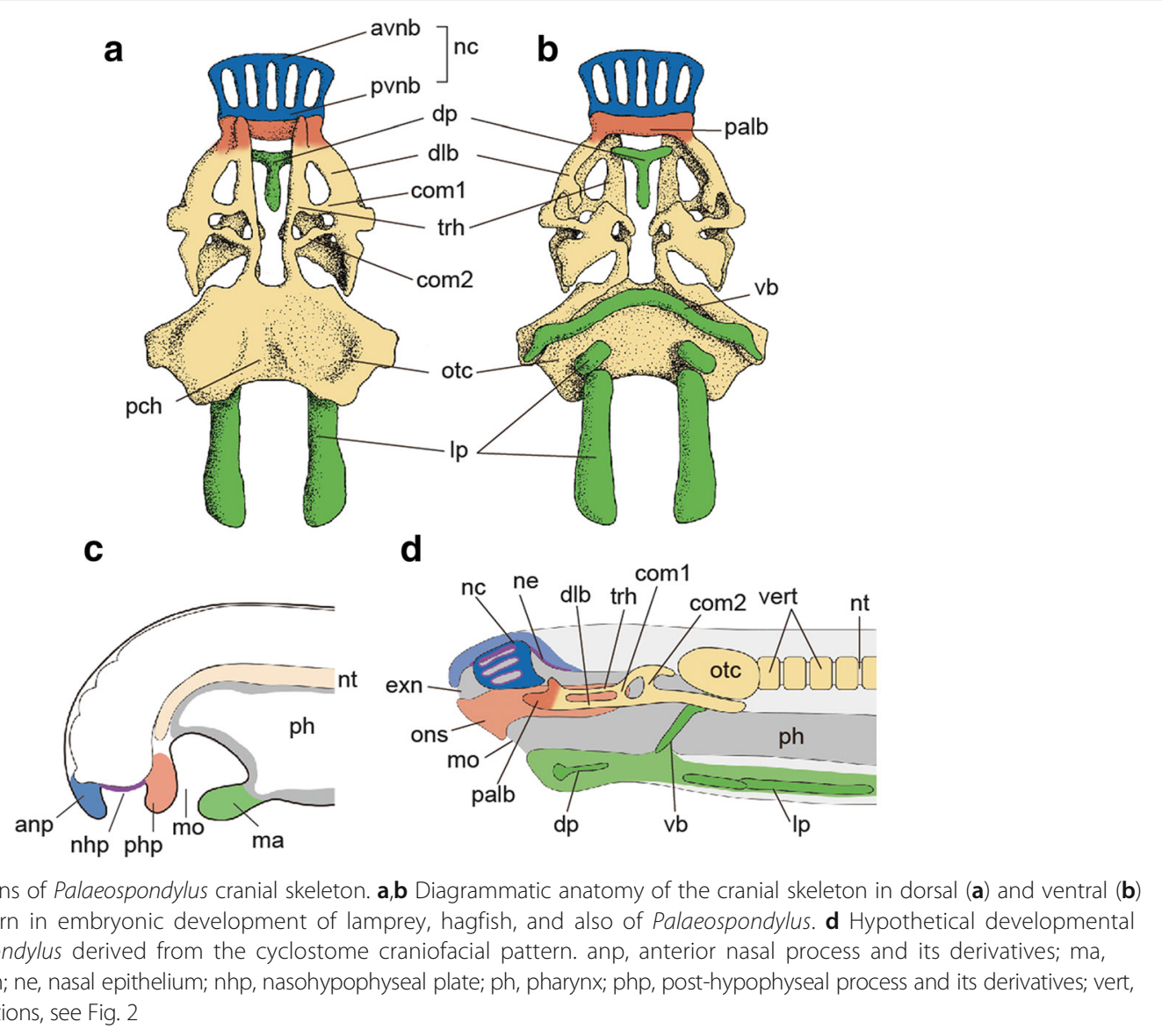

explain the apparent absence of more posterior branchial arches in Palaeospondylus. The ventral, median Tshaped skeletal element in Palaeospondylus, often called the 'tauidion' [5] (Fig. 1b), may occur distant from the neurocranium [5, 8, 9, 26] (Additional file 2: Figure S2), and we suggest that it is comparable to the hagfish dental plate (Figs. 2b, d and 3b, Additional file 2: Figure S2). In the previous gnathostome hypothesis, this 'tauidion' has been analogized to the gnathostome vomer [10], but that identification is less plausible, as the 'tauidion' was independent of the other cranial elements. The absence of dermal bones in Palaeospondylus [11] also argues against the interpretation of the 'tauidion' as the gnathostome vomer, which is a dermal bone.

Two paired skeletal plates cover the ventral aspect of the caudal half of Palaeospondylus cranium (Fig. 1). The rostral pair is located at the level of the otic capsule, and the larger caudal pair covers the ventral aspect at the levels of the caudal half of the otic capsule and the rostral vertebral elements (Fig. 1b). These plates likely represent the lingual apparatus of the hagfish (Fig. 3b), as proposed also by Bulman [8]. These plates were later identified as lungfish-specific cranial ribs (occipital ribs)
[10]. This view, however, is not consistent with the absence of the cranial rib in larval lungfishes [27, 28].

\section{Discussion}

The history of studies on Palaeospondylus [1-10] constitutes a heuristic search for homologous body parts, a task that we suggest may be completed with the present study, in which it was finally compared with the hagfish embryo. Previous studies comparing Palaeospondylus with hagfishes relied solely on adult morphology [8]. Importantly, it has recently been shown that adult hagfish species possess vestigial vertebral elements [21]. The presence of a vertebral column composed of cylindrical vertebrae in Palaeospondylus (Additional file 1: Figure S1), which simply sheathed the notochord [5, 8], thus does not necessarily preclude its affinity with the modern hagfish. Our comparative analysis of Palaeospondylus and the hagfish embryo, revealing previously unrecognized topographical relationships between skeletal elements specific to these taxa, was made possible by the introduction of modern techniques to the study of hagfish embryonic development in recent years [20-23, 29]. 
According to comparative developmental biology two mutually exclusive systems of craniofacial anatomical configuration are present in vertebrates [22, 24]. In both, during embryonic development, the rostral portion of the cephalic crest-derived ectomesenchyme (trigeminal crest cells) initially follows a common distribution pattern, comprising the pre- and postoptic crest cells and mandibular arch crest cells (up to early pharyngula stage) [30]. However, the difference between the cyclostomes and crown gnathostomes later becomes conspicuous (Additional file 3: Table S1) in association with differences in placode distribution [22, 31]. In cyclostomes, the craniofacial morphology develops from the mandibular arch (MA), post-hypophyseal process (PHP), and anterior nasal process (ANP) [24, 32]. In crown gnathostomes, the embryonic head consists of lateral and medial nasal prominences (LNP, MNP), postoptic ectomesenchyme (PO), maxillary and mandibular processes (MX, MN) [24, 32]. Given that the craniofacial pattern of stem gnathostomes (osteostracans and galeaspids) conforms with the cyclostome pattern [22], the cyclostome pattern (involving MA, PHP, and ANP) thus represents the ancestral developmental pattern for the total-group vertebrates, whereas the crown gnathostome pattern (involving LNP, MNP, PO, MX, and MN) represents a derived condition. However, the craniofacial development of crown gnathostomes does not, even transiently, recapitulate the cyclostome pattern at any developmental stage [22, 24].

The Palaeospondylus cranium is congruent with the cyclostome craniofacial pattern described above (Fig. 3). In this comparison, the nasal capsule, subnasal rostral cranium (palatine bar, and rostral part of the dorsal longitudinal bar and trabecula), and dental and lingual plates of the Palaeospondylus are reconstructed to develop from the ANP, PHP and MA of the cyclostome pattern, respectively (Fig. 3c,d; Additional file 4: Table S2). The inferred positions of the nasal epithelium and adenohypophysis in Palaeospondylus are consistent with this scheme (Fig. 3d). Contrastingly the Palaeospondylus cranium cannot be derived from the crown gnathostome pattern, which involves a dorsoventrally bifurcated mandibular arch, separate paired nostrils, and adenohypophysis. A previous hypothesis that suggested a Devonian lungfish affinity of Palaeospondylus [10] was flawed in that it did not account for the neurocranial element developed medially to MX.

More detailed homology relationship of skeletal elements can be established between Palaeospondylus and the hagfish embryo at specific developmental stages, but not with the lamprey skeletal elements at any developmental stage. The cage-shaped nasal capsule, two separated longitudinal bars (the dorsal longitudinal bar and trabecula), velar bar, and large lingual plates (Fig. 3a, b) are seen exclusively in the hagfish embryo and Palaeospondylus, and the topographical arrangement of these homologous elements is consistent. Based on these synapomorphies, it is parsimonious that Palaeospondylus was related to hagfishes.

A comparison of the rostral portion of the neurocranium among vertebrates further underscores the congruence between Palaeospondylus and the hagfish. There is a morphological disparity among the crown gnathostomes, lamprey and hagfish, which results from the difference in 'trabeculae' within embryonic heads; in fact, the term 'trabecula' does not designate the same body part among the crown gnathostomes, lamprey and hagfish. The neurocranium of the crown gnathostomes is heterogeneous in cell lineage [30,33]; the rostral part, or trabecula, develops from the cephalic neural crest cells [34-38], while the caudal part, or parachordals, from the mesoderm [33]. In the cyclostomes, a large part of the rostral portion of the neurocranium develops from mesodermal cells [23, 39-43], and only the nasal capsule and oropharyngeal skeleton develop from the cephalic (ANP and PHP, respectively) crest cells [24, 44]. In the lamprey, the trabecula ('lamprey trabecula') consists of a mesodermal neurocranial wall secondarily elongated rostrally [39-43]. In the hagfish, the corresponding prechondrogenic precursor later splits dorsoventrally into two bars: the dorsal longitudinal bar and 'hagfish trabecula' $[23,24]$. Of these, the configuration of rostral elements of Palaeospondylus neurocranium agrees only with the hagfish-type, as the dorsal longitudinal bar and 'hagfish trabecula' occupy the corresponding position in this taxon.

One previous study argued against the cyclostome affinity of Palaeospondylus, citing the presence of a paired fin located caudally distant from the cranium [9]. The extant hagfishes, on the other hand, possess a cartilage at the origin of the lingual muscle (the 'cyclostome tongue' [45]), or the perpendicular muscle cartilage, which is located far caudal to the cranium [46] (Fig. 4). The perpendicular muscle cartilage of the extant hagfish is not decay-prone [47], and thus can be preserved separately from the cranial skeleton in fossils. Here, we suggest that the 'paired fin' of Palaeospondylus may in fact represent such a skeletal element at the origin of the lingual muscle.

Unique among known cyclostomes, Palaeospondylus possessed distinct features, including the biomineralization of cartilages and the well-developed vertebral column (notochordal centrum). These features, however, may have evolved from cyclostome-like conditions. The calcified cartilage of Palaeospondylus lacked perichondral ossification [48], which is specific to the gnathostomes [38], and it is conceivable that the calcified cartilage of Palaeospondylus evolved either through loss of perichondral ossification in gnathostomes, or through 


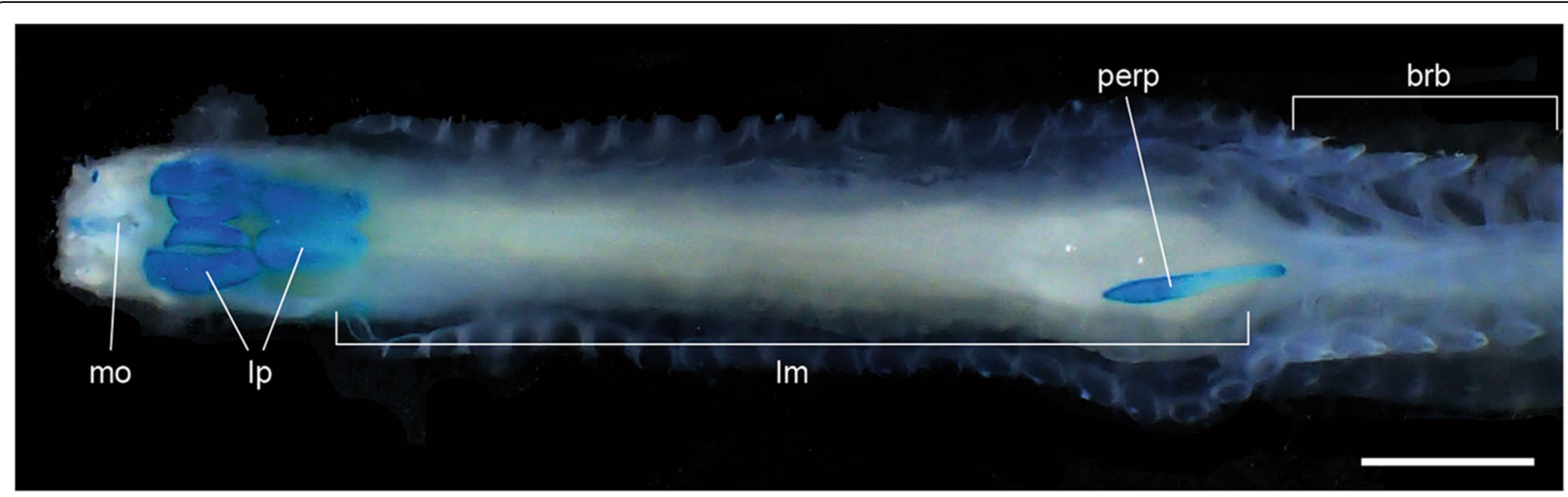

Fig. 4 Alcian blue-stained specimen of the adult hagfish Eptatretus burgeri in ventral view. brb, branchial bascket; Im, lingual muscle ('cyclostome tongue'); Ip, lingual plate; mo, mouth; perp, perpendicular muscle cartilage (cartilage at the origin of the lingual muscle). Scale bar, $1 \mathrm{~cm}$

acquisition of biomineralization in cyclostomes. The latter possibility appears more plausible, as the hypertrophied cell lacunae in the cartilages of Palaeospondylus $[11,48]$ are reminiscent of cyclostome cartilages in their thin layers of extracellular matrix [21, 49]. A recent study also suggested that the vertebral element is synapomorphic to the vertebrates [21, 50], and the cylindrical vertebral column in Palaeospondylus (Additional file 1: Figure S1) may have evolved secondarily from arcualia in basal cyclostomes, through the invasion of cartilaginous cells into the fibrous sheath within the elastica externa [51]. The absence of arcualia in Palaeospondylus fossils does not preclude this scenario, since calcification often occurs differentially among vertebral elements, as seen in elasmobranchs [52].

There are nonetheless minor differences between Palaeospondylus and the known hagfish species, including the absence of some skeletal elements in Palaeospondylus. We suggest that this is likely due to a taphonomic bias. In the extant cyclostomes, there are two types of cartilage, hard and soft, which differ in the amount of extracellular matrix $[49,53,54]$. Soft cartilage is less resistant to decay than hard cartilage [47]. A similar heterogeneity of cartilage composition may have been present in Palaeospondylus, given that the branchial skeleton has not been identified in Palaeospondylus. The absence of branchial skeleton in Palaeospondylus fossils may indicate that cartilages of the branchial basket were not calcified, as in extant cyclostomes, for the functional reason that the branchial basket changes shape during ventilation. Among fossil cyclostomes, the Late Devonian putative stem-lamprey Euphanerops is a unique taxon that possessed calcified branchial basket [55]. The gill basket of Euphanerops was, however, unique in extending caudally across the half of the trunk, suggesting a functional requirement different from that in other cyclostomes.
In the extant hagfish chondrocranium, the rostralmost skeletal element made of hard cartilage is the subnasal cartilage (Fig. 2e). The subnasal cartilage is expected to be found rostral to the nasal capsule [47], but is apparently missing in Palaeospondylus. Since the proportion of the Palaeospondylus cranium resembles the embryonic, rather than the adult, cranium in known hagfish species (Fig. 2e), the absence of overt subnasal cartilage in Palaeospondylus fossils may reflect a very short snout containing a delicate subnasal cartilage. Cartilages supporting the nasal duct and tentacles in the extant hagfish are composed of soft cartilage [54], thus they are expected to decay rapidly.

Given the potential extensive taphonomic bias and the lack of data about soft tissue anatomy unlike circumstances of other species [56-58], it is difficult to build a character matrix to conduct a cladistic analysis of Palaeospondylus. Nevertheless, the above comparison strongly suggests that Palaeospondylus and the hagfish share a cranial skeletal configuration that is distinguishable from those of the lamprey and crown gnathostomes. On the other hand, some features seen in adult individuals of the known hagfish species are less conspicuous in Palaeospondylus. In particular, in the extant hagfishes, as well as in the Late Carboniferous hagfish Myxinikela siroka [59], the position of the nasal capsule, which initially develops at the rostral end of the cranium becomes relatively caudal in the cranium of adult individuals, whereas in Palaeospondylus, the nasal capsule remained at the rostral end. Based on this synapomorphy between extant hagfishes and Myxinikela, we suggest that the phylogenetic position of Palaeospondylus is best explained as a stem hagfish lineage basal to Myxinikela (Fig. 5).

The hagfish affinity of Palaeospondylus is important for the time of divergence between hagfish and lamprey lineages. The oldest reliable fossil record of the 


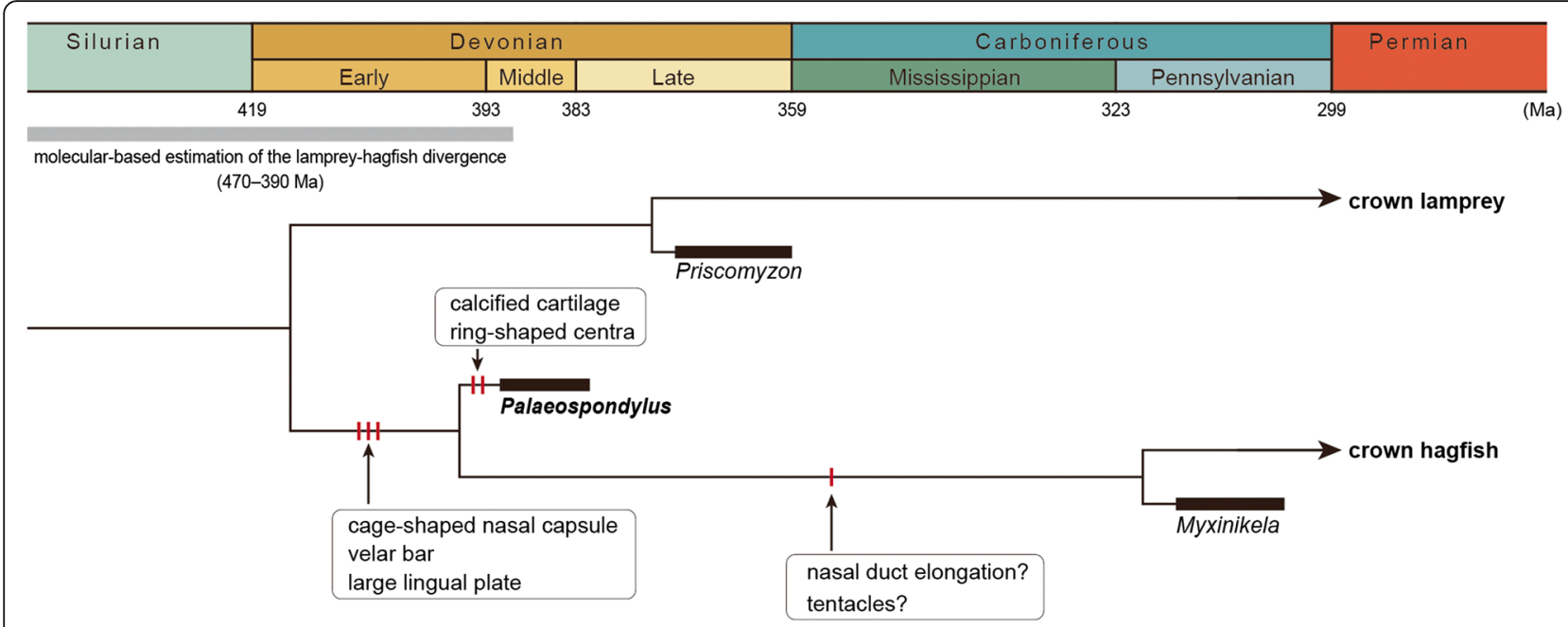

Fig. 5 Proposed phylogenetic position of Palaeospondylus. The molecular-based estimation of the lamprey-hagfish divergence was adopted from [63]

divergence time is the fossil lamprey Priscomyzon riniensis from the Upper Devonian (Famennian: 372$359 \mathrm{Ma}$ in [60]) [61, 62]. An estimate using nucleotide and amino acid sequences, however, dated the divergence time to 470-390 Ma [63] (by the Middle Devonian), leaving a gap between the molecular-based estimate and the fossil record. Our classification of Palaeospondylus into the hagfishes pushes the oldest fossil record of the divergence time back to the Middle Devonian (393-383 Ma, Fig. 5), filling the gap between the molecular estimate and the fossil record, as well as depicting a hagfish species before the endDevonian mass extinction that wiped out many vertebrate groups, including placoderms [64, 65].

Early cyclostomes may thus have been more morphologically diverse than previously recognized. At present, the early evolution of the cyclostomes has been less clear than that of the gnathostomes [62, 65]. Further analysis of Palaeospondylus, as well as other putative cyclostomes in the fossil record [55, 58, 66], may shed new light on the evolution of this lineage.

\section{Conclusions}

We identified congruences in the arrangement of a suite of homologous skeletal parts between Palaeospondylus and the hagfish embryo, and conclude that Palaeospondylus was closely related to hagfishes. The gnathostome affinity of this species is improbable, since the topography of cranial skeletal elements of Palaeospondylus is consistent exclusively with the developmental craniofacial pattern of the cyclostomes. Palaeospondylus more closely resembles the embryo than the adult of the extant hagfish, suggesting that this species is placed at a stem hagfish position basal to the hitherto known hagfish species in the phylogeny.

\section{Additional files}

Additional file 1: Figure S1. Fossils of Palaeospondy/us from the Middle Devonian of the Scotland. (a) entire specimen of Palaeospondylus gunni (AMNH FF 10743) in ventral view. (b) cranial skeleton of P. gunni (AMNH FF 7586) in dorsal view. (c) Line drawing of B. (d) cranial skeleton of $P$. gunni (AMNH FF 10742) in ventral view. (e) Line drawing of D. amp, ampyx; $\mathrm{cp}$, caudal plate; gam, gammation; hem, hemidome; otc, otic capsule; ros, rostralia; rp, rostral plate; ve, V-shaped element; vert, vertebra. Scale bar, 1 mm. (JPG $3 \mathrm{mb}$ )

Additional file 2: Figure S2. Referred Palaeospondylus specimens illustrated in previous studies. (a,b) A specimen in dorsal (a) and ventral (b) views, from [26]. (c,d) three-dimensional model reconstructed from sections in dorsal (c) and ventral (d) views, from [5]. (e) NHM (Natural History Museum, London) P 16123 in dorsal view, from [8]. (f), NHM P 16125 in ventral view, from [8]. amp, ampyx; cp, caudal plate; gam, gammation; hem, hemidome; otc, otic capsule; ros, rostralia; ve, V-shaped element; vert, vertebra. (JPG $860 \mathrm{~kb})$

Additional file 3: Table S1. Comparison of craniofacial primordia in cyclostomes and crown gnathostomes. Based on [22]. (DOC $29 \mathrm{~kb}$ )

Additional file 4: Table S2. Comparison of cranial skeletal elements among extant cyclostomes and Palaeospondylus. Names of skeletal elements in Palaeospondylus are shown by abbreviations employed in the present paper. For the nomenclature of the lamprey and hagfish chondrocrania, see [23]. (DOC $38 \mathrm{~kb}$ )

\section{Acknowledgements}

We thank Kinya G. Ota and Osamu Kakitani for collecting and preparing specimens of hagfish embryos, Satoko Fujimoto for preparing Alcian blue-stained hagfish specimens, John Maisey and Alana Gishlick for fossil specimen access, and Douglas Sipp for useful comments.

Funding

This study was funded by RIKEN. 


\section{Availability of data and material}

The data supporting the conclusions of this article are included within the article and its additional files. The fossil specimens examined in this article are kept in American Museum of Natural History, New York, USA.

\section{Authors' contributions}

TH and SK designed the project. YO and SK obtained data about the hagfish embryology. TH examined fossils of P. gunni. TH and SK prepared figures and wrote the manuscript. All authors read and approved the final manuscript.

\section{Competing interests}

The authors declare no competing financial interests. Readers are welcome to comment on the online version of the paper.

\section{Consent for publication}

Not applicable.

\section{Ethics approval and consent to participate}

Not applicable.

\section{Author details}

'Evolutionary Morphology Laboratory, RIKEN, 2-2-3 Minatojima-minami, Chuo-ku, Kobe, Hyogo 650-0047, Japan. ${ }^{2}$ Development and Function of Inhibitory Neural Circuits, Max Planck Florida Institute for Neuroscience, Jupiter, FL 33458, USA.

Received: 29 June 2016 Accepted: 30 August 2016

Published online: 08 September 2016

\section{References}

1. Traquair RH. On the fossil fishes at Achanarras Quarry, Caithness. Ann Mag Nat Hist 6th Ser. 1890:6:479-86.

2. Dawson JW. Some salient points in the science of the earth. London: W. Drysdale and Co.; 1893

3. Kerr JG. The zoological position of Palaeospondylus (Traquair). Proc Camb Philol Soc. 1900;10:298-9.

4. Dean B. Still another memoir on Palaeospondylus. Science. 1904;19:425-6.

5. Sollas WJ, Sollas IBJ. An account of the Devonian fish Palaeospondylus gunni Traquair. Philos Trans R Soc Lond B. 1904;196:267-94.

6. Stensiö EA. The Downtonian and Devonian vertebrates of Spitsbergen. Part I, Family Cephalaspidae. Skr Svalbard Nordishavet. 1927;12:1-391.

7. Miller AE. Note on the tail skeleton of Lepidosiren paradoxa, with remarks on the affinities of Palaeospondylus. Proc Zool Soc Lond. 1930;100:783-9.

8. Bulman OMB. Note on Palaeospondylus gunni, Traquair. Ann Mag Nat Hist 10th Ser. 1931:8:179-90.

9. Moy-Thomas JA. The Devonian fish Palaeospondylus gunni Traquair. Philos Trans R Soc Lond B. 1940:230:391-413.

10. Thomson KS, Sutton M, Thomas B. A larval Devonian lungfish. Nature. 2003; 426:833-4.

11. Johanson Z, Kearsley A, den Blaauwen J, Newman M, Smith MM. No bones about it: An enigmatic Devonian fossil reveals a new skeletal framework: A potential role of loss of gene regulation. Semin Cell Dev Biol. 2010;21:414-23.

12. Joss J, Johanson Z. Is Palaeospondylus gunni a fossil larval lungfish? Insights from Neoceratodus forsteri development. J Exp Zool Part B Mol Dev Evol. 2007:308B:163-71.

13. Newman MJ, Den Blaauwen JL. New information on the enigmatic Devonian vertebrate Palaeospondy/us gunni. Scot J Geol. 2008:44:89-91.

14. Colbert EH. Evolution of the vertebrates. 2nd ed. New York: Wiley; 1969.

15. Patterson C. Morphological characters and homology. In: Joysey KA, Friday $A E$, editors. Systematics association special volume 21: problems of phylogenetic reconstruction. London: Academic; 1982. p. 21-74.

16. Hall BK. Homoplasy and homology: Dichotomy or continuum? J Hum Evol. 2007:52:473-9.

17. Wagner GP. Homology, genes, and evolutionary innovation. Princeton: Princeton Univ Press; 2014

18. Sereno PC. Logical basis for morphological characters in phylogenetics. Cladistics. 2007;23:565-87.

19. Ramirez MJ. Homology as a parsimony problem: a dynamic homology approach for morphological data. Cladistics. 2007;23:588-612.
20. Ota KG, Kuraku S, Kuratani S. Hagfish embryology with reference to the evolution of the neural crest. Nature. 2007:446:672-5.

21. Ota KG, Fujimoto S, Oisi Y, Kuratani S. Identification of vertebra-like elements and their possible differentiation from sclerotomes in the hagfish. Nat Commun. 2011:2:373.

22. Oisi Y, Ota KG, Kuraku S, Fujimoto S, Kuratani S. Craniofacial development of hagfishes and the evolution of vertebrates. Nature. 2013;493:175-80.

23. Oisi Y, Ota KG, Fujimoto S, Kuratani S. Development of the chondrocranium in hagfishes, with special reference to the early evolution of vertebrates. Zool Sci. 2013;30:944-61.

24. Kuratani S, Oisi Y, Ota KG. Evolution of the vertebrate cranium: viewed from the hagfish developmental studies. Zool Sci. 2016;33:229-38.

25. Dean B. On the embryology of Bdellostoma stouti. A genera account of myxinoid development from the egg and segmentation to hatching. In: Festschrift zum siebenzigsten Geburtstag von Carl von Kupffer. Jena: Gustav Fischer; 1899. p. 220-76.

26. Traquair $\mathrm{RH}$. A still further contribution to our knowledge of Palaeospondylus gunni. Proc R Soc Edinb. 1893;12:312-21.

27. Greil A. Entwickelungsgeschichte des Kopfes und des Blutgefäßsystems von Ceratodus forsteri. II. Die epigenetischen Erwerbungen während der Stadien 39-48. Denkschr Med-Naturwiss Ges Jena. 1913:4:935-1492.

28. Johanson Z, Ericsson R, Long J, Evans F, Joss J. Development of the axial skeleton and median fin in the Australian lungfish, Neoceratodus forsteri. Open Zool J. 2009;2:91-101.

29. Ota KG, Kuratani S. The history of scientific endeavors towards understanding hagfish embryology. Zool Sci. 2006;23:403-18.

30. Wada N, Nohno T, Kuratani S. Dual origins of the prechordal cranium in the chicken embryo. Dev Biol. 2011:356:529-40.

31. Kuratani S. Evolution of the vertebrate jaw from developmental perspectives. Evol Dev. 2012;14:76-92.

32. Haeckel E. Anthropogenie oder Entwickelungsgeschichte des menschen: Keimes- und stammesgeschichte. Leipzig: W. Engelmann; 1877.

33. Couly GF, Coltey PM, Le Douarin NM. The triple origin of skull in higher vertebrates: a study in quail-chick chimeras. Development. 1993;117:409-29.

34. Le Douarin N. The neural crest. Cambridge: Cambridge Univ Press; 1982.

35. Maderson PFA, editor. Developmental and evolutionary aspects of the neural crest. New York: Wiley; 1987.

36. Hall BK, Hörstadius S. The neural crest. New York: Oxford Univ Press; 1988.

37. Kuratani S. Craniofacial development and the evolution of the vertebrates: the old problems on a new background. Zool Sci. 2005:22:1-19.

38. Hirasawa T, Kuratani S. Evolution of the vertebrate skeleton: morphology, embryology, and development. Zool Lett. 2015;1:2.

39. Johnels AG. On the development and morphology of the skeleton of the head of Petromyzon. Act Zool. 1948;29:139-279.

40. Kuratani S, Murakami Y, Nobusada Y, Kusakabe R, Hirano S. Developmental fate of the mandibular mesoderm in the lamprey, Lethenteron japonicum: comparative morphology and development of the gnathostome jaw with special reference to the nature of the trabecula cranii. J Exp Zool Part B Mol Dev Evol. 2004:302B:458-68.

41. Newth DR. Experiments on the neural crest of the lamprey embryo. J Exp Biol. 1951;28:247-60.

42. Newth DR. On the neural crest of the lamprey embryo. J Emb Exp Morphol. 1956:4:358-75.

43. Langille RM, Hall BK. Role of the neural crest in development of the trabeculae and branchial arches in embryonic sea lamprey, Petromyzon marinus (L). Development. 1988;102:301-10.

44. Dupret V, Sanchez S, Goujet D, Tafforeau P, Ahlberg PE. A primitive placoderm sheds light on the origin of the jawed vertebrate face. Nature. 2014;507:500-3.

45. Oisi Y, Fujimoto S, Ota KG, Kuratani S. On the peculiar morphology and development of the hypoglossal, glossopharyngeal and vagus nerves and hypobranchial muscles in the hagfish. Zool Let. 2015;1:6.

46. Marinelli W, Strenger A. Vergleichende anatomie und morphologie der wirbeltiere. II. Myxine glutinosa (L.). Wien: Franz Deuticke; 1956

47. Sansom RS, Gabbott SE, Purnell MA. Decay of vertebrate characters in hagfish and lamprey (Cyclostomata) and the implications for the vertebrate fossil record. Proc R Soc Lond B. 2011:278:1150-7.

48. Johanson Z, Kearsley A, den Blaauwen J, Newman M, Smith MM. Ontogenetic development of an exceptionally preserved Devonian cartilaginous skeleton. J Exp Zool Part B Mol Dev Evol. 2012;318B:50-8.

49. Ota KG, Kuratani S. Expression pattern of two collagen type 2 a1 genes in the Japanese Inshore Hagfish (Eptatretus burgeri) with special reference to 
the evolution of cartilaginous tissue. J Exp Zool Part B Mol Dev Evol. 2010; 314B:157-65.

50. Ota KG, Oisi Y, Fujimoto S, Kuratani S. The origin of developmental mechanisms underlying vertebral elements: implications from hagfish evo-devo. Zoology. 2014;117:77-80.

51. Gadow HF. The evolution of the vertebral column: a contribution to the study of vertebrate phylogeny. Cambridge: Cambridge Univ Press; 1933.

52. Ridewood WG. On the calcification of the vertebral centra in sharks and rays. Philos Trans R Soc Lond B. 1921;210:311-407.

53. Parker WK. On the skeleton of the Marsipobranch fishes. Part I. The Myxinoids (Mixyine, and Bdellostoma). Philos Trans R Soc Lond. 1883;174:373-409.

54. Cole FJ. A monograph on the general morphology of Myxinoid fishes, based on a study of Myxine. Part 1. The anatomy of the skeleton. Trans $R$ Soc Edinb. 1905;41:749-88.

55. Janvier P, Arsenault M. The anatomy of Euphanerops longaevus Woodward, 1900, an anaspid-like jawless vertebrate from the Upper Devonian of Miguasha, Quebec, Canada. Geodiversitas. 2007:29:143-216.

56. Shu DG, Conway Morris S, Han J, Zhang ZF, Yasui K, Janvier P, et al. Head and backbone of the Early Cambrian vertebrate Haikouichthys. Nature. 2003; 421:526-9.

57. Conway Morris S, Caron JB. A primitive fish from the Cambrian of North America. Nature. 2014:512:419-22.

58. McCoy VE, Saupe EE, Lamsdell JC, Tarhan LG, McMahon S, Kidgard S, et al. The 'Tully monster' is a vertebrate. Nature. 2016;532:496-9.

59. Bardack D. First fossil hagfish (Myxinoidea) - a record from the Pennsylvanian of Illinois. Science. 1991;254:701-3.

60. Walker JD, Geissman JW, Bowring SA, Babcok LE. compilers: Geological Time Scale v. 4.0. Boulder: Geological Society of America; 2012

61. Gess RW, Coates MI, Rubidge BS. A lamprey from the Devonian period of South Africa. Nature. 2006:443:981-4.

62. Janvier P. Early jawless vertebrates and cyclostome origins. Zool Sci. 2008;25: 1045-56.

63. Kuraku S, Kuratani S. Time scale for cyclostome evolution inferred with a phylogenetic diagnosis of hagfish and lamprey cDNA sequences. Zool Sci. 2006:23:1053-64.

64. Sallan LC, Coates MI. End-Devonian extinction and a bottleneck in the early evolution of modern jawed vertebrates. Proc Natl Acad Sci U S A. 2010; 107:10131-5.

65. Friedman M, Sallan LC. Five handred million years of extinction and recovery: a phanerozoic survey of large-scale diversity patterns in fishes. Palaeontology. 2012;55:707-42.

66. Kuratani S, Hirasawa T. Palaeontology: Getting the measure of a monster. Nature. 2016:532:447-8.

\section{Submit your next manuscript to BioMed Central and we will help you at every step:}

- We accept pre-submission inquiries

- Our selector tool helps you to find the most relevant journal

- We provide round the clock customer support

- Convenient online submission

- Thorough peer review

- Inclusion in PubMed and all major indexing services

- Maximum visibility for your research

Submit your manuscript at www.biomedcentral.com/submit

) Biomed Central 